\title{
A DIFÍCIL CONSTRUÇÃO DA LIDERANÇA SOLIDÁRIA COMPARTILHADA
}

\author{
THE DIFFICULT CONSTRUCTION OF \\ SHARED SOLIDARITY LEADERSHIP
}

Marília Veríssimo Veronese*

Robinson Scholz**

RESUMO: Este artigo tem como tema central a questão da liderança no contexto do trabalho autogestionário, discutindo as possibilidades e limites de uma liderança solidária compartilhada na autogestão. Busca-se compreender o fenômeno por meio da análise das diferentes lógicas de solidariedade que operam no âmbito da economia solidária. Metodologicamente, utilizamos um estudo de casos múltiplos, realizado junto a três empreendimentos econômicos solidários, de segmentos de atuação diferenciados, na cidade de São Leopoldo/ RS. Os conceitos de economia solidária e de liderança são abordados em uma perspectiva sociológica, e os dados foram coletados com base na observação, análise de corpus documental e entrevistas semiestruturadas. Para a análise dos dados foi utilizada a técnica da Análise de Conteúdo Temático. As conclusões apontam para a complexidade e as contradições que caracterizam as múltiplas lógicas de solidariedade existentes entre os atores sociais, no contexto dos empreendimentos. Destaca-se a importância da compreensão sobre as permutas sociais em curso, com vistas ao crescimento do sujeito por meio da aprendizagem coletiva e cooperativa, possibilitando a experimentação e o desenvolvimento da prática da liderança solidária compartilhada.

Palavras Chave: Economia Solidária; Liderança; Lógicas de Solidariedade; Autogestão; Grupos.

\footnotetext{
* Doutora em Psicologia Social e Professora do Programa de Pós-Graduação em Ciências Sociais da Universidade do Vale do Rio dos Sinos - UNISINOS, São Leopoldo, RS; e-mail: MariliaV@unisinos.br ** Mestre em Ciências Sociais Aplicadas, Doutorando em Ciências Sociais no Programa de Pós-Graduação em Ciências Sociais da Universidade do Vale do Rio dos Sinos - UNISINOS, São Leopoldo, RS; e-mail: robinsonscholz@hotmail.com
} 
ABSTRACT: This article has as central theme, the issue of leadership in the context of self-managed work, trying to understand the phenomenon through different solidarity logics operating in the solidary economy. Methodologically, we used a multiple-case study in three solidary economy enterprises in different sectors of activity in the city of São Leopoldo/RS. The concepts of solidary economy and leadership are approached under a sociological perspective, and the data were collected based on observation, analysis of a documental corpus and half-structured interviews. For data analysis, we used the technique of the Thematic Content Analysis. The conclusions point to the complexity and contradictions of the logics of solidarity between social actors and their importance in the enterprising context. It is highlighted the relevance of understanding ongoing social exchanges in enterprises, aiming at the growth of the individual through collective and cooperative learning, allowing the experimentation and development of the practice of a shared solidary leadership.

Keywords: Solidary economy; Leadership, Solidarity logics. Self-management; Groups.

\section{INTRODUÇÃO}

As formas de gestão e organização da vida em sociedade são cotidianamente produzidas em diversos cenários e contextos socioeconômicos. Nestes espaços institucionalizados, identificam-se variadas formas de relações sociais entre os sujeitos envolvidos em cada esfera organizacional, cuja forma de condução política diferencia-se de uma instituição para outra. A busca de novos conhecimentos relacionados à liderança e suas consequências em um determinado contexto instiga a delimitar o campo de análise, de forma que se possa compreender a práxis da liderança em maior profundidade no contexto do trabalho associativo e cooperativo.

A economia solidária hoje, no Brasil, cresce como campo de práticas econômicas calcadas em noções de justiça, equidade, responsabilidade social e ambiental. Segundo Gaiger (2009, p. 181) 
"O conceito de empreendimento econômico solidário compreende diversas modalidades de organização econômica, originadas da livre associação de trabalhadores/as, nas quais a cooperação funciona como esteio de sua eficiência e viabilidade". As experiências, dentre as quais se destacam grupos de produção, associações formais e informais, cooperativas e empresas de autogestão, praticam (em graus bastante variados) a socialização dos meios de produção e a autogestão. Dentre seus pressupostos estão a valorização da comunidade de trabalho e o compromisso com a coletividade em que se inserem.

Nesse sentido, o tema é abordado no âmbito dos empreendimentos econômicos solidários (EES), sendo que a reflexão empreendida é de que a autogestão é uma forma autônoma de trabalho e as atividades que dela decorrem estão em constante mudança, ora na produção, ora nas decisões estratégicas do EES. À luz dos princípios norteadores da economia solidária, compreende-se que não há como participar de todas as ações - desde a produção até a gestão - ao mesmo tempo. Parte-se do princípio, contudo, que os trabalhadores associados poderão desenvolver e aprender competências necessárias à prática da liderança solidária compartilhada (esse pressuposto baseia-se em evidências das observações). Tal processo, contudo, certamente será difícil e não livre de conflitos. Com base nesta reflexão, busca-se entender como se configuram as lógicas relacionais no interior dos EES e como é possível compreender as representações e as práticas efetivas da liderança ali vivenciadas.

\section{ECONOMIA SOLIDÁRIA}

A economia solidária abrange um amplo espectro de expectativas, experiências e práticas. Como princípios geradores de sua ética, estão os valores de boa convivência humana entre si e com o meio ambiente, sustentabilidade social e ambiental. Muitas experiências populares de produção econômica e de geração de renda, no Brasil e em outros países, estariam formando uma economia popular fundada na cooperação solidária e integrada à economia de mercado, segundo lógicas não exclusivamente mercantis. 
O objetivo do empreendimento solidário é a obtenção da quantidade e da qualidade do produto ou serviço que venha a atender a demanda social, e não somente maximizar o lucro com a venda do produto ou serviço. $\mathrm{O}$ excedente terá sua destinação decidida pelos trabalhadores em assembléia, pois a propriedade e concepção coletivas dos meios e modos de gestão do trabalho é característico do empreendimento solidário, seja ele cooperativo, associativo ou comunitário.

A autogestão é outro critério importante no campo; ela diferencia-se da heterogestão na qual um patrão, chefe, supervisor, ou consultor nos modelos de gestão contemporâneos, decide, orienta e define os rumos dos processos e das relações $d a$ e $n a$ produção. $\mathrm{Na}$ autogestão, cada um deverá ser gestor, discutindo em grupo quais são as ações prioritárias, como férias, ganhos financeiros etc. É um processo difícil, um dos maiores desafios desses empreendimentos, talvez mesmo seu ponto nevrálgico. O sujeito é interpelado a ser seu próprio gestor, geralmente tendo toda uma história de subordinação nas experiências anteriores de trabalho.

Revisando a literatura sobre economia solidária, percebese que muitos dos EES se constituíram na tentativa de fazer frente aos problemas da conjuntura socioeconômica, como o desemprego estrutural e a pauperização da classe que vive do trabalho, tendo significativo crescimento nos anos de 1990. Contudo, é preciso dizer que, sozinha, a crise econômica não explica o surgimento da economia solidária. As iniciativas comunitárias/associativas de geração de trabalho e renda, que eclodem no início dos anos 1980 e multiplicam-se nos 90, têm por motivos de criação fatores diversos, tais como aspirações de pobreza digna, valorização da comunidade, desejo de propriedade própria dos meios de produção por parte dos trabalhadores, além de apoios externos provenientes de setores progressistas da Igreja Católica e outras entidades. Se as razões fossem somente a crise financeira e a depauperação da relação assalariada, enormes contingentes de pessoas optariam pela economia solidária. No entanto, esse universo não chega a dois milhões de participantes, segundo dados do Primeiro Mapeamento Nacional ${ }^{1}$. Os dados do

\footnotetext{
${ }^{1} \mathrm{O}$ primeiro mapeamento da economia solidária no Brasil foi finalizado em 2006 e teve por ob44| Século XXI, Revista de Ciências Sociais, v.3, nº 2, p.41-64, jul./dez. 2013 ISSN: $2236-6725$
} 
segundo mapeamento ainda estão em análise nesse momento, não tendo sido publicados (setembro de 2013).

A economia solidária é regida por princípios, os quais, pelo menos supostamente, se espera que estejam internalizados na compreensão e na prática dos sujeitos das experiências associativas: autogestão, democracia, participação, igualitarismo, cooperação, autossustentação, desenvolvimento humano e responsabilidade social (Gaiger, 2004). Igualmente, a economia solidária valoriza o território e compromete-se com a localidade prioritariamente presente no mercado intrarregional, procurando uma forma apropriada de uso do capital natural de forma compatível com a melhor qualidade de vida da população residente, ou seja, é vetor de um desenvolvimento endógeno e sustentável (Lisboa, 2001). Potencialidades locais, estimuladas por meio das práticas de economia solidária, podem gerar o crescimento local e sustentável.

Esses princípios, obviamente, são vivenciados e aplicados em graus muito variáveis, existindo experiências quase modelares e outras que se afastam bastante das práticas solidárias e cooperativas em sua formulação ideal. Não se deve confundir a descrição feita nas bases de um tipo ideal weberiano, que é um instrumento teórico analítico em que são descritas todas as características possíveis de um fenômeno, com a realidade concreta. Através da elaboração de "tipologias puras", ou seja, destituídas de tom avaliativo, oferece um recurso analítico baseado em conceitos. Não são, contudo, modelos a serem encontrados na realidade empírica. O próprio EES pode ser considerado, na sua descrição completa, um tipo ideal. Os empreendimentos "reais" se aproximarão ou se afastarão desse modelo ideal, e esse é o interesse da análise em relação, também, ao tipo ideal da liderança solidária compartilhada, que se caracteriza por um líder empreendedor, mas também empoderador, catalisador da participação de todos (Scholz e Veronese, 2008).

Os EES formalizam-se de diversas formas e em variados cenários. Uma das possibilidades materializa-se quando empregados

jetivo realizar um diagnóstico socioeconômico dos empreendimentos econômicos solidários e das instituições de apoio e fomento. 
de empresas fabris em processo de falência assumem o controle destas, junto com o desafio de construir modelos de autogestão democráticos e eficazes, capazes de garantir a sobrevivência e expansão no mercado (Guimarães, 2000). Outra forma de edificação pode se efetivar pelas associações de pessoas desprovidas de trabalho e renda, mas com anseio na busca de alternativas para a sua sobrevivência e portadoras de conhecimentos específicos, agregando valores para a sua associação (Suarez, 1992). Os EES possuem diversas formas de organização, podendo ser uma cooperativa ou associação de produção agrícola, extrativa ou industrial; uma cooperativa ou associação que reúne pequenos produtores autônomos (agricultores, taxistas, recicladores de lixo, etc.); clubes de troca; clubes de poupança; cooperativas de consumo, de crédito, habitacionais; grupos informais e assim por diante (Singer, 2003).

Em relação às formas de organização dos empreendimentos no que diz respeito à formalização jurídica e estrutural, os dados do mapeamento nacional permitiram verificar quais as possibilidades existentes e mais praticadas. Segundo a publicação da cartilha Economia Solidária - Mapeamento Rio Grande do Sul (2008), dos 21.857 empreendimentos mapeados no Brasil, $52 \%$ se organizam em forma de associação, sendo o formato organizativo mais expressivo. A segunda forma de organização mais apresentada é a de grupo informal, com frequência de $36 \%$. Com $10 \%$ de representatividade, apresentam-se as cooperativas e os $2 \%$ resultantes se organizam em forma de sociedade mercantil. Ainda com base nos dados do mapeamento, $48 \%$ dos empreendimentos são exclusivamente rurais, $35 \%$ urbanos e 17\% são rurais e urbanos. Os EES investigados nesta pesquisa são urbanos e fazem parte do referido mapeamento.

O papel da economia solidária é basicamente:

[...] uma nova experimentação, cujo sentido para os atores é determinante dos rumos que virá a tomar, seja no registro pragmático de respostas às necessidades, seja na razão projetiva que os pode conduzir a novos horizontes. Aqui, revela-se o papel fundamental da experiência como fonte de aprendizado, da formulação de solu- 
ções e caminhos, posto que não haja hábitos culturais estabelecidos, respostas prévias, tecnologias à mão, sistemas de apoio e tudo mais, validado e difundido (Gaiger, 2004, p.14).

Existe na sociedade um campo de lutas sociais, no qual se inserem as práticas de economia solidária como uma proposta de geração de trabalho e renda baseada em valores que vão para além do estritamente econômico. Ou eventualmente ampliam a concepção do econômico incluindo o atendimento das demandas sociais e comunitárias, a distribuição equitativa dos bens etc. Mas a própria compreensão do campo não é homogênea, ora sendo ela entendida como uma resposta contrária ao capitalismo, ora como inserção ocasional dos indivíduos marginalizados na sociedade e fora do alcance da empregabilidade, ou ainda como funcional ao capitalismo. Esses tensionamentos fazem parte do processo e os atores que vivem do trabalho associado e participam do movimento social, além de agentes apoiadores de ONGs, gestores públicos, universidades etc., se esforçam por melhor definir e entender o campo, além de fortalecê-lo nos seus aspectos emancipatórios e empoderadores.

$\mathrm{O}$ trabalho associativo traz à tona um ator fundamental, posto que é realizado em coletivos: o grupo de trabalho.

\section{O GRUPO}

O conceito de grupo é discutido por diversas correntes nas ciências humanas e sociais, sendo muitas as suas definições, de acordo com o contexto a ser trabalhado. Na sua origem etimológica, o vocábulo "grupo" é uma reunião de coisas que forma um todo distinto, uma reunião de certo número de pessoas, ou, então, uma pequena associação ou reunião de pessoas ligadas por um mesmo objetivo.

São inúmeras as modalidades de abordagem grupal, as quais divergem desde a conceituação até o desenvolvimento da prática em si. Entretanto, conforme afirma Barros (1996), constituiu-se, a partir do século XIX, um modo de apreensão do conceito de grupo que centra-se em torno de algumas constantes. Nesta concepção, o grupo 
é percebido como "um intermediário entre o indivíduo e a sociedade; o grupo é um todo; é uma estrutura, é uma unidade, é um objeto de investigação" (Barros, 1996, p. 98). Essa mesma autora considera uma outra construção do conceito de grupo, percebendo-o como um dispositivo. O grupo seria composto de elementos heterogêneos que, ao encontrarem-se, acionam modos de funcionamento diversos, que produzirão certos efeitos (Barros, 1996, p. 105).

Como as formas de organização da economia solidária são associações de pessoas que buscam objetivos em comum, percebe-se que o trabalho autogestionário tende a ser um dispositivo de compreensão sobre como se gerenciam e se constituem tais coletivos de trabalho. É o grupo tentando compreender a si mesmo ao agir. Conforme estudos de Kurt Lewin, é importante saber “[...] quem tomou a iniciativa da formação do grupo, quem está na origem da autoridade existente no grupo, e qual é a função ocupada pelo grupo na sociedade em que se insere" (Mailhiot, 1991, p.124). Segundo as observações de nosso trabalho empírico, os sujeitos, nos EES, acabam valorizando e respeitando quem acredita em algo e demonstra capacidade de alcançar resultados positivos na produção e comercialização. Na percepção dos sujeitos, se os líderes tiverem em mente ideologias e práticas cooperativas e de solidariedade, podem unir as distintas ordens ou níveis que permeiam a cooperação e legitimar sua posição de liderança:

[...] as doutrinas, às quais está subjacente um conteúdo utópico, orientam normativamente para o que deve ser, tratando de superar a realidade atual, com uma visão quase profética do destino em direção ao qual deve orientar-se a humanidade. A teoria, como ciência do que é, conhecendo a realidade como é, trata de encontrar os mecanismos adequados para - considerando comportamentos reais poder organizar a cooperativa de tal maneira que se realizem os fins imediatos para os quais foi criada e possibilita - embora somente a longo prazo - a orientação paulatina em direção aos horizontes para os quais a doutrina aponta com o normativo (Villegas, 1979, p. 81). 
A experimentação do trabalho coletivo, seja qual for o formato organizacional de um empreendimento, terá a liderança como um fator importante para seu desenvolvimento, utilizando possíveis elementos tais como confiança, união, comunicação, estratégias de condução das ações e tomadas de decisão, todas implicadas em relações sociais e laços de solidariedade. A seguir, são relacionadas teorizações e reflexões sobre a liderança, intentando relacioná-las com as práticas da economia solidária.

\section{LIDERANÇA E O RELACIONAMENTO SOCIAL}

Para realizarmos a análise acerca das relações sociais desenvolvidas pelos sujeitos e as dinâmicas de grupos nos quais eles se constituem, partimos de alguns conceitos e autores de base. De Moscovici (1991), tomamos a discussão sobre o consenso, fator fundamental para a associação, o agir em comum acordo e as tomadas de decisões em um determinado grupo social. De Senge (2004), a idéia de que a confiança e o desenvolvimento interpessoal são requisitos para a formação de relações e associações voluntárias, sendo essenciais para a ativação política de cidadãos. De Bajoit (2006), a teorização sobre as lógicas de ação em grupo.

A liderança, a partir de vários autores, é aqui compreendida como um atributo não somente individual, mas também do âmbito coletivo e suas relações, produzido por um imaginário simbólico de um determinado grupo social, um espírito da coletividade que faz compreender a melhor direção a ser seguida naquele momento histórico (Gramsci, 2004; Gardner, 1996; Kernberg, 2000).

Kernberg (2000) alerta para o fato de que seguir o líder idealizado reconstitui uma identidade própria, por identificação com ele/a, protegendo o indivíduo da agressão intragrupal por meio desta identidade comum. Pela projeção compartilhada da agressão sobre inimigos externos, gratificam-se as necessidades de dependência mediante a submissão ao líder, mas nem sempre o resultado será favorável, democrático ou positivo, caracterizando uma situação de risco à construção da autogestão. 
Evidentemente que a vida coletiva, em sociedade, em grupos, pressupõe a resolução de dificuldades fundamentais levantadas pela nossa coexistência, problemas que se não resolvidos e direcionados à ação coletiva, podem pôr em risco a integridade individual de cada pessoa envolvida no grupo (Bajoit, 2006). Assim, cada indivíduo é pressionado pelos outros a tomar decisões que possam resolver os problemas da vida coletiva e, assim, mesmo que algumas pessoas tenham resoluções efetivas, os líderes acabam sendo os detentores de fatia significativa do poder de decisão final. As histórias e narrativas dos grupos são fundamentais para a coesão das pessoas envolvidas, pelo fato de que, através do histórico de vida, elas exprimem o sentido de identidade e pertencimento ao grupo em que estão envolvidos. Outro um ponto fundamental no papel do líder é o de promover acesso às narrativas históricas do grupo social e a sua legitimação, realizando a interlocução entre os sujeitos (Bajoit, 2006).

Lewin (1978) defendia em seus estudos que os indivíduos podem fazer parte de variados grupos sociais, e a causa das dificuldades não é pertencer a muitos grupos, e sim a incerteza de pertencer ou não. Em uma sociedade de classes, há grupos privilegiados, legitimados e reconhecidos pela sociedade, cujo acesso é facilitado e há movimento ativo pelos indivíduos e redes de parceiros. Por outro lado, há grupos desprivilegiados, que estão na fronteira da marginalização, a ponto de não serem reconhecidos pela sociedade e tampouco pelos próprios integrantes do grupo como possuindo alternativas credíveis de vida. Esta incerteza de estar ou não inserido em um grupo privilegiado ou desprivilegiado é que remete o indivíduo a permanecer entre um e outro, em transição, o que ocasiona desgaste individual e despotencialização dos grupos na sua ação coletiva. Pode-se relacionar essa discussão com os EES, pois são grupos de geração de trabalho e renda em constante modificação, com consideráveis índices de rotatividade e que, por ser uma proposta de organização do trabalho ainda recente, há uma resistência ao ingresso e o compromisso das pessoas nestes espaços. São constituídos geralmente por trabalhadores pobres, com um caráter em alguma medida precário de vida. Ao entrarem num modo de trabalho cooperativo, os 
sujeitos por vezes se comprometem com a proposta, por vezes não, encarando como um meio de sobrevivência passageiro. Ambas as experiências coexistem no interior do grupo.

Em relação ao compromisso, Bajoit (2006, p. 235) considera que cada indivíduo, estando em constante processo de (re)constituição, assume perante si mesmo compromissos identitários: "têm uma certa ideia daquilo que é e do que queria vir a ser e daquilo que acredita dever fazer para isso". Para a realização desses acordos, cada um precisa do(s) outro(s), ou seja, deve-se entrar em relações sociais com eles, participando de trocas, permutas e tecendo laços sociais. Logo, cada indivíduo estabelece lógicas de ação com os outros, acabando por construir a sua identidade pessoal com, contra, apesar de, em virtude de, e entre eles. Este processo contribui na construção do ator social, estando ele compromissado nas lógicas de ação por ele estabelecida na relação com o(s) outro(s). No grupo autogestionário, esse processo assume contornos muito interessantes, sendo o mote de nossa análise nesse trabalho.

Bajoit (2006) teoriza que na solidariedade afetiva, a troca é subjetiva, e os indivíduos efetuam suas relações de compromisso de forma expressiva; dão afeto e o recebem em troca, para a realização da sua identidade pessoal. Quando as trocas são materiais ou instrumentais, os indivíduos realizam a solidariedade contratual, que obedece a uma relação objetiva e muito menos subjetiva. Quando as coisas que estão em troca, em relação, são de qualidade subjetiva, temos a lógica expressiva, cujo interesse está na necessidade de desenvolvê-las por meio de grupos, fundindo a identidade pessoal com a dos outros, que, juntos, fornecem qualidades que não haveria se estivessem sozinhos, gerando a denominada solidariedade fusional. Em contrapartida, quando uma identidade pessoal passa a ter força e segurança somando-se com as de outros, criando um grupo forte, denomina-se de solidariedade serial. Em suma, estas quatro lógicas de solidariedade expressam a necessidade de articulação com os outros na produção contínua de suas identidades pessoais. 


\section{CAMINHOS METODOLÓGICOS DA PESQUISA}

Esta investigação parte de um estudo de casos múltiplos, de abordagem qualitativa, tendo como campo empírico três empreendimentos de diferentes ramos de atuação, localizados na cidade de São Leopoldo/RS, a aproximadamente trinta quilômetros da capital, Porto Alegre.

A investigação foi realizada na Associação Reciclar², uma associação de reciclagem composta por 25 trabalhadores atuantes na triagem dos resíduos sólidos; no Grupo Corte e Vida, um grupo informal composto por 07 associados atuantes na área do artesanato e costura; e na Cooperativa Metal, uma cooperativa metalúrgica autogestionada, constituída por 32 associados que reuniram-se para desenvolver um trabalho coletivo após perderem seus empregos em 2002, quando a empresa para a qual trabalhavam pediu falência.

Interessante destacar ainda alguns aspectos dos empreendimentos investigados. O primeiro é em relação à organização jurídica, uma vez que foram pesquisadas uma associação, uma cooperativa e um grupo informal. Nesse sentido, é importante ressaltar que essas diferenças são fruto do processo histórico de constituição de cada EES, uma vez que esses coletivos emergem em contextos diferentes. A Associação Reciclar emerge a partir das frentes de trabalho organizadas pelo Movimento dos Trabalhadores Desempregados (MTD), tendo como grande motivador os movimentos sociais e a luta pelo direito ao trabalho. Já a Cooperativa Metal é fundada por ex-trabalhadores de uma empresa falida, os quais assumem os meios de produção e desenvolvem o trabalho da cooperativa. O movimento sindical tem grande participação no apoio ao processo de constituição da cooperativa, bem como na negociação com a empresa falida para a recuperação dos meios de produção em troca das indenizações trabalhistas. E por fim, o Grupo Corte e Vida surge a partir de ações terapêuticas promovidas pelo Posto de Saúde local, no âmbito do Programa de Saúde da Família (PSF), com a finalidade de proporcionar um espaço de reconstrução e resgate da cidadania dos moradores da comunidade. As discussões eram sobre saúde,

${ }^{2}$ Nomes fictícios dados aos EES para preservar a identidade de cada empreendimento. 
gênero, trabalho e família, bem como um espaço para aprendizado de trabalhos manuais, atividades laborais e ocupacionais, o que proporcionou, com o passar dos encontros, a ideia de organizar um empreendimento que pudesse unir as pessoas que faziam parte desse grupo e comercializar os objetos artesanais por elas confeccionados.

Um segundo aspecto pode ser destacado sobre os sujeitos pesquisados, no que se refere aos seus processos de ação e aprendizagem em experiências pregressas. A experimentação de cargos de coordenação do trabalho produtivo em empresas, a atuação como lideranças comunitárias e de movimentos sociais, fazem parte das vivências desses líderes, de suas histórias de vida e puderam contribuir para a constituição dos empreendimentos em foco. Conforme já mencionado, os contextos históricos de emergência de cada EES permitem o desenvolvimento de vivências - como a dimensão subjetiva da experiência - de modo a constituir cada empreendimento. Assim, os sujeitos desenvolvem suas práticas de formas distintas, conforme influência do meio de origem histórica; contudo, se adequam e atualizam algumas questões para o exercício da liderança no contexto da economia solidária. Essas lógicas de ação são por vezes complementares e contraditórias, e serão são discutidas a seguir.

O um terceiro aspecto é que os empreendimentos fizeram parte do Primeiro Mapeamento da Economia Solidária, realizado pela Secretaria Nacional de Economia Solidária, vinculada ao Ministério do Trabalho e Emprego do Brasil e seus dados estão tabulados no Sistema Nacional de Informações em Economia Solidária (SIES) ${ }^{3}$.

O corpus 4 de dados foi composto por meio de 20 entrevistas semiestruturadas com os informantes, somando mais de 200 páginas de entrevistas decupadas e digitadas e 12 observações de campo registradas durante as visitas (Bauer e Aarts, 2002).

Para que se tenha uma visão mais próxima dos sujeitos da pesquisa, segue quadro de identificação dos informantes:

\footnotetext{
${ }^{3}$ Disponível em: http://www.mte.gov.br/ecosolidaria/sies.asp

${ }^{4} \mathrm{O}$ conceito de corpus é definido como "uma coleção finita de materiais, determinada de antemão pelo analista com (inevitável) arbitrariedade e com a qual ele irá trabalhar, o que acentua a natureza proposital da seleção, não apenas de textos, mas também de qualquer material com funções simbólicas" (Bauer e Gaskell, 2002, p. 44-45).
} 
Quadro 01: Quadro de Identificação dos Sujeitos da Pesquisa

\begin{tabular}{|c|c|c|c|c|}
\hline Informante* & Gênero & $\begin{array}{c}\text { Idade } \\
\text { (anos) }\end{array}$ & EES & $\begin{array}{c}\text { Tempo de } \\
\text { atuação (anos) }\end{array}$ \\
\hline André & Masc & 27 & Metal & 2 e $1 / 2$ \\
\hline Adair & Masc & 52 & Metal & 7 \\
\hline Amanda & Fem & 81 & Metal & 7 \\
\hline Rosemar & Fem & 55 & Metal & 7 \\
\hline Lúcio & Masc & 58 & Metal & 7 \\
\hline Rinaldo & Masc & 38 & Metal & 4 \\
\hline Gisela & Fem & 46 & Corte e Vida & 4 \\
\hline Doraci & Fem & 56 & Corte e Vida & 1 \\
\hline Ingrid & Fem & 47 & Corte e Vida & $1 / 2$ \\
\hline Isis & Fem & 60 & Corte e Vida & 4 \\
\hline Márcia & Fem & 40 & Corte e Vida & 4 \\
\hline Amanda & Fem & 43 & Reciclar & 7 \\
\hline Jerônimo & Masc & 28 & Reciclar & 7 \\
\hline Juliana & Fem & 18 & Reciclar & $1 \mathrm{e} 1 / 2$ \\
\hline Marta & Fem & 24 & Reciclar & 1 \\
\hline Marcelo & Masc & 37 & Reciclar & 3 \\
\hline Magali & Fem & 51 & Reciclar & 7 \\
\hline Rute & Fem & 31 & Reciclar & 1 e $1 / 2$ \\
\hline Carla & Fem & 28 & Reciclar & 5 \\
\hline Aline & Fem & 27 & Reciclar & 7 \\
\hline & & & \\
\hline
\end{tabular}

Fonte: Elaborado pelos autores.

* Os nomes são pseudônimos, a fim de preservar a identidade dos entrevistados

Este quadro permite um olhar sobre os sujeitos, sua faixa etária e tempo de atuação no empreendimento, o que pode acabar refletindo nas relações de liderança, outro ponto interessante de análise para pesquisas futuras.

Os dados foram analisados com base na técnica da Análise de conteúdo temática, tal como apresentada por Laurence Bardin (2008). Segundo a autora, ao analisarmos um conjunto de entrevistas, verificamos que os discursos não são homogêneos, possuem contradições e ambivalências; assim é necessário fazer deles uma síntese possível, que sirva para elucidar os elementos de sentido expressos nas temáticas centrais, a serem extraídas e interpretadas pelo analista. Deveria ser um discurso que tomasse em consideração tanto os traços comuns às diferentes entrevistas como as suas diferenças, organizando-os na 54| Século XXI, Revista de Ciências Sociais, v.3, nº 2, p.41-64, jul./dez. 2013 
medida do possível. A análise realizada foi de cunho qualitativo, semântico (também chamada "construtivista"). Trata-se de buscar núcleos de sentido, temas relevantes que gerem conhecimento sobre o objeto pesquisado (neste caso, as lógicas de solidariedade presentes naqueles grupos de empreendedores associados).

Buscamos a produção de inferências, propiciando a passagem da descrição à interpretação, para ir além do material bruto, buscando construir o conhecimento sobre o objeto de estudo, que se revela no discurso dos sujeitos - relacionam-se as estruturas semânticas com as estruturas sociológicas, a partir da base teórica utilizada.

$\mathrm{Na}$ seção a seguir, são apresentados alguns dos resultados da pesquisa, ilustrando qualitativamente as lógicas de solidariedade presentes nos EES investigados, lógicas estas que permitem uma reflexão sobre as potencialidades e limitações ou incompletudes da liderança solidária compartilhada.

\section{AS LÓGICAS DE SOLIDARIEDADE E LIDERANÇA SOLI- DÁRIA COMPARTILHADA}

Avaliamos que os indivíduos, ao se associarem a um EES, necessitam atingir certos objetivos individuais, como geração de renda, apoio social, inserção comunitária etc. Quando do início da sua participação, consideram, geralmente, ser aquele apenas mais um espaço de trabalho, que possuiria características semelhantes aos arranjos empresariais já vivenciados em experiências laborais anteriores. Com base nesse entendimento inicial, o indivíduo cria permutas contraditórias, não aceitando diretamente que nos espaços de atuação da economia solidária exista a possibilidade de outro arranjo organizacional e, por isso, há o processo de explicitação em duas vias: o novo associado coloca para o grupo o que pretende e o grupo explica o que precisa do sujeito, bem como esclarece a dinâmica de trabalho do EES. O novo integrante se associa ao grupo porque já conhece alguém de dentro do EES, articulando, em primeira instância, a solidariedade afetiva para com o grupo. Em referência às lideranças, ele entende que o empreendimento é uma empresa e que deve estar subordinado a uma pessoa 
que ordenará suas atividades e exercerá coerção sobre ele, compreendendo, nesta primeira etapa, como sendo uma liderança tradicional weberiana. Assim, as lógicas de interação possuem elementos variados, e as entendemos como contraditórias.

Com o processo da elaboração das permutas sociais em andamento, o indivíduo passa a competir com os seus pares dentro do EES, enraizado aos modelos mentais do mercado capitalista vigente, promovendo permutas competitivas no seio do EES. Essas permutas não são as únicas que surgem, pois o indivíduo sofre influência dos processos de complexificação do grupo. Suas atividades coletivas são reforçadas e suas competências de relacionamento testadas, conforme o grau de evolução do empreendimento. Nessa esteira relacional do trabalho, emerge a solidariedade contratual, no sentido de verificar as atividades concretas realizadas, tendendo à objetividade da permuta, cujo cunho econômico está em voga. Ou seja, o sujeito percebe que precisa produzir, dar um resultado, oferecer uma contribuição concreta aos objetivos do grupo.

Ao lidar com a premência da produtividade, os sujeitos tendem a superar a etapa anterior, baseada no solidarismo e na agregação de um novo associado que necessita construir sua identidade pessoal por meio de atividades laborais. Assim, as regras e normatizações ganham força devido à complexidade das exigências do trabalho e do relacionamento social que engendra. O indivíduo tende a se esforçar mais, a aprender mais sobre o EES e sua cultura de trabalho. Nesta etapa, a liderança passa a ser entendida como mais próxima da liderança racional-legal, cujo poder e autoridade estão em quem direciona o grupo, regula as atividades e ocupa uma posição de comando e controle (por exemplo, coordenador, presidente, tesoureiro, conselheiro etc.). A liderança também sofre esse processo evolutivo e pedagógico, no sentido de sua apreensão e representação, estando ela sempre sendo testada e avaliada pelos indivíduos, conforme as complexidades do trabalho que permeiam o EES.

Superada a segunda fase evolutiva dentro do empreendimento, o indivíduo continua aprendendo coisas novas sobre a dinâmica do grupo social e tende a estabelecer novas permutas com os seus pares 
de trabalho. As permutas conflituais ganham espaço entre os atores sociais, no sentido de promover a cooperação entre eles, estabelecendo laços sociais que possibilitem a solidariedade fusional no EES.

Uma vez que a aprendizagem para o trabalho autogestionário está sendo aprimorada e provocando rupturas com os modelos empresariais anteriores, dá-se espaço à emergência de novos modelos mentais, embasados nos princípios da economia solidária. Como o indivíduo atinge este nível de abstração e entendimento da realidade a qual está inserido? Por meio do processo de escalada que instiga os atores a permanecerem nas permutas sociais já estabelecidas e buscam novas permutas com os associados, pela própria natureza do trabalho coletivo e autogestionário. A cooperação torna-se algo necessário.

Nesta dinâmica relacional, as experiências que ele proporciona podem, ou não, desestabilizar esquemas cognitivos anteriores, pode provocar assimilação de novos esquemas. Nessa fase, a aprendizagem para o trabalho coletivo é de extrema dificuldade, demandando alto nível de esforço dos atores e a busca do comprometimento socioeconômico para com o grupo. A liderança já mostra-se através de um outro entendimento, não necessariamente em substituição aos anteriores, mas convivendo com eles, sobrepondo-se, acrescentando algo novo. Denominamos esta fase liderança solidária devido ao fato de que os atores sociais já percebem com outro discernimento a proposta do trabalho coletivo, das suas responsabilidades e da necessidade de participação nas instâncias estratégicas do empreendimento. E começam a perceber que todos, incluindo eles/as próprios/ as, podem eventualmente assumir papéis de liderança perante os pares. Reforçamos que não se trata de superar fases cronológicas, mas acrescentar as lógicas e vivenciá-las com todas as ambiguidades e contradições típicas dos processos relacionais humanos.

Anteriormente, quando trabalhavam em empresas convencionais (heterogestão), os indivíduos eram subordinados a um líder ou chefe; agora, eles mesmos já podem executar ações de liderança, participando nas tomadas de decisão. Esse processo de mudança tende a ser lento e descontínuo. Formalmente, ainda há pouca descentralização nas relações de poder e autoridade no grupo social, caben- 
do a alguns que já possuam maior competência desenvolver a prática da liderança formal, instituída em assembleia. Mas, para além dessa prática, as lideranças informais estão presentes na condução das atividades produtivas do EES e se constituem enquanto tal, o que já significa uma mudança interessante e potencialmente um dispositivo de emancipação para os sujeitos (entendendo a emancipação como empoderamento pessoal e social, cotidianamente vivenciado).

Avançando nesse processo de enriquecimento formativo, o indivíduo eventualmente atinge um alto patamar evolutivo com base na aprendizagem e acomodação das três etapas anteriores. Relacionando-se com mais esmero no empreendimento e com suas permutas sociais fortalecidas e mantidas, os atores sociais promovem as permutas complementares, que se validam das competências dos indivíduos e da cooperação dos mesmos para melhor alcançar as finalidades do grupo. Nesta etapa, os indivíduos tendem a possuir maiores competências para o trabalho coletivo e autogestionário, além de já terem apreendido, em partes, a racionalidade da economia solidária e promoverem a solidariedade serial, obtendo mais força e segurança com a união de atores sociais engajados em atingir objetivos e finalidades coletivas.

Entende-se que nesse momento há o processo de avaliação dos indivíduos; pois uma vez que já se conhecem melhor, experienciaram processos de aprendizagem para o trabalho coletivo e autogestionário, aprenderam a conhecer as condutas do outro e a comunicação passa a ser melhor efetivada entre os associados. Outrossim, eles aprendem conjuntamente os processos de trabalho produtivo e estratégico, engajam-se na proposta do EES e difundem as informações e os conhecimentos inerentes ao grupo entre os associados. Potencialmente, ocorre a emergência da liderança solidária compartilhada que irá (re) distribuir constantemente as responsabilidades dentro do grupo, descentralizando o poder em níveis homogêneos e horizontais. É bem verdade que esse processo dá-se em patamares diversos, nos diferentes empreendimentos. A lógica do ideal buscado pelos grupos é a de que cada indivíduo possa ter as competências necessárias para a liderança, colocando-as em prática, uma vez que todos são donos-sócios-usuários do empreendimento. Claro que essa emergência é uma 
possibilidade, que vai efetivar-se em graus muito variáveis, mas a sua presença é claramente observável em alguns momentos.

Por fim, atingida esta possibilidade, a ação coletiva é alcançada e os associados assimilam os traços socioculturais por eles mesmos, mobilizando os atores sociais para o alcance das finalidades coletivas do grupo e arquitetando a identidade coletiva do EES. Na ocorrência da interação das lideranças solidárias compartilhadas, este processo torna-se fortalecido e possível de ser praticado, além de conduzir os novos associados ao mesmo processo pelos quais passaram, desenvolvendo mecanismos pedagógicos de apropriação cultural e organizacional e valorizando o solidarismo e o empreendedorismo necessários ao EES. Sendo um processo pedagógico, percebemos que a liderança solidária compartilhada também o é, interpretada à luz da figura 1 a seguir:

Figura 1 - Processo de aprendizagem para a liderança solidária compartilhada.

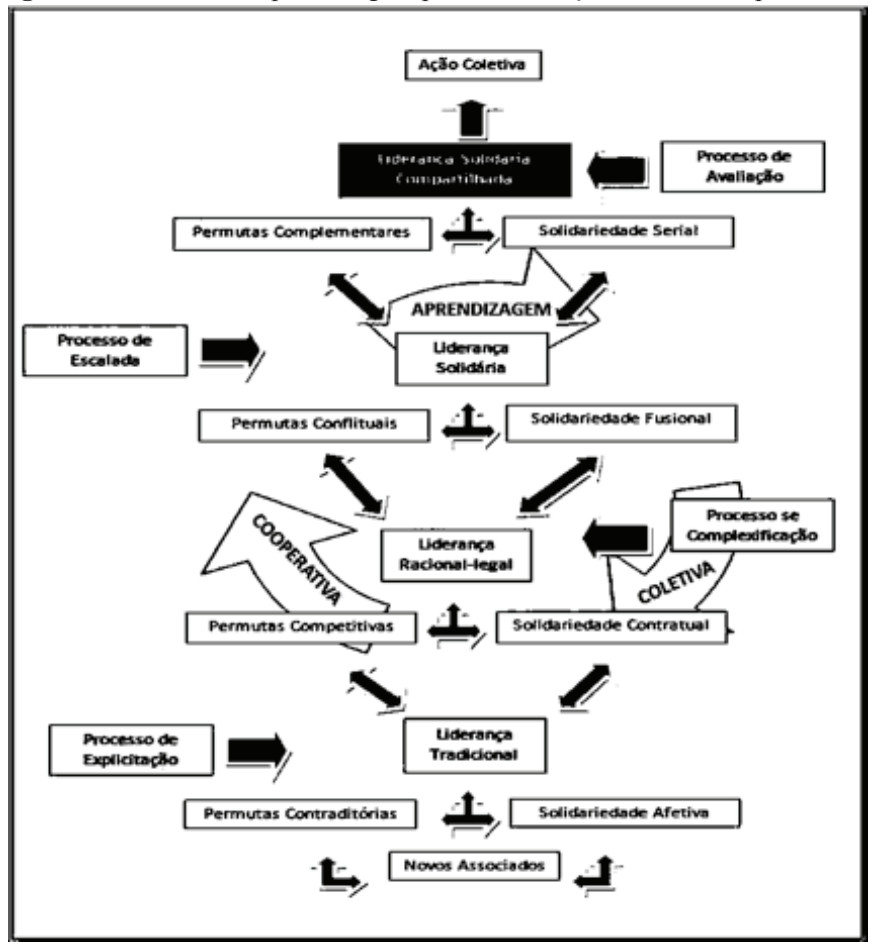

Fonte: Elaborado pelos autores.

59| Século XXI, Revista de Ciências Sociais, v.3, nº 2, p.41-64, jul./dez. 2013 
O entendimento em profundidade das complexidades inerentes ao processo acima apresentado é a forma mais apropriada de condução das atividades sociais e econômicas nos EES, salientando que este processo é constante e não-linear, uma vez que os indivíduos podem não evoluir cronologicamente em cada etapa, podendo regredir, ascender novamente na escala de evolução, estagnar-se ou pular etapas, dependendo do nível de competências e de aprendizado que possuem ou do nível de comprometimento em apreender os processos socioculturais do EES. Importante deixar claro que não temos uma perspectiva de "progresso" contínuo, de patamares "inferiores" para "superiores", mas sim de processualidade, na qual diferentes experiências conduzem (são dispositivos) de diferentes lógicas. Mas a tendência de um coletivo de trabalho bem estruturado, à medida que desenvolve e pratica a autogestão, é ir construindo a liderança solidária. Utilizamos o termo "complexidade" segundo Edgar Morin. Para esse autor, um pensamento complexo:

(...) parte de fenômenos ao mesmo tempo complementares, concorrentes e antagonistas, respeita as coerências diversas que se unem em dialógicas e polilógicas e, com isso, enfrenta a contradição por várias vias. (Morin 2000, p. 387)

Ou seja, ao mesmo tempo em que não há linearidade nem direção automática no processo de aprendizagem dos trabalhadores, há a possibilidade de atingirem patamares elevados em termos da prática da liderança solidária (autoridade compartilhada). Não há, contudo, nenhuma garantia que isso vá acontecer inexoravelmente; depende de muitas possíveis combinações, lógicas, entendimentos, relações que se estabelecem. O esquema acima ilustra uma possibilidade, dentre outras, não um processo automático. Ele representa aquilo que encontramos como potencial desenvolvimento dos processos de liderança nos grupos, mas em absoluto há qualquer garantia que será assim. Entendemo-lo como potencialidade a ser agenciada, mais que modelo a ser seguido.

Destacamos que o líder solidário (qualquer trabalhador/a no 
momento em que assume esse papel, não somente o líder formal) possui as competências necessárias para a execução da tarefa (comunicação, conhecimento técnico e educacional, empatia, confiança, paciência, transparência, etc.); toma as decisões democraticamente em reuniões; representa o empreendimento nos contextos externos e articula-se politicamente, além de também operacionalizar o processo produtivo igualitariamente com os demais associados. Esse perfil, obviamente, precisa ser entendido como um tipo ideal weberiano: não encontraremos tal e qual na realidade empírica, mas sua descrição nos auxilia a perceber o quanto os líderes podem se afastar ou se aproximar mais do perfil de liderança solidária compartilhada.

As evidências empíricas também apontam para a existência de perfis de líderes não identificados com essa aquisição de aprendizagem, detentores de poder que centralizam as informações e a condução dos processos de gestão do EES, mostrando as eventuais permanências de relações de dominação sobre os indivíduos no grupo social. Por isso o processo é contraditório e não linear. Modos diversos de liderança coexistem, sustentados por lógicas de relacionamento híbridas e não lineares.

\section{CONSIDERAÇÕES FINAIS}

A partir desses resultados, na perspectiva da formação para a prática da autogestão, pudemos pensar na importância do exercício de autoconhecimento e autorreflexão pelos indivíduos em torno das relações sociais e de trabalho executadas nos EES. Este exercício permite a constante dinâmica de avaliação e apropriação cultural, uma vez que as racionalidades em torno da economia solidária são diferenciadas para cada um dos envolvidos, que potencialmente são passíveis de produzir (e transformar) o contexto.

Uma vez compreendidas as permutas sociais que os sujeitos estabelecem e as solidariedades que estão presentes na teia social que tecem, pode-se lidar melhor com os processos de comando e uso de poder existente no EES. Tendo esta análise em mente, salientamos como os grupos promovem espaços de aprendizagem coletiva e 
cooperativa para, aí sim, estabelecer modelos pedagógicos que possibilitem a apropriação da liderança solidária compartilhada. Estes modelos necessitam estar em constante aplicação e reformulação, uma vez que é um processo contínuo, não linear e que demanda esforços para a sua eficácia. Havendo estímulo por parte dos atores sociais já envolvidos com o grupo e o interesse dos novos associados, o processo tende a ser mais bem conduzido e o grupo a funcionar como dispositivo de empoderamento dos/as trabalhadores/as pobres, para além da geração de renda.

O engajamento num processo desse tipo, produtor de autoridade compartilhada, significa um ganho não material: obtenção de crescimento cognitivo, vivências emocionais positivas e crescimento da autoestima, em termos individuais e grupais.

O psicólogo social cubano Fernando González Rey (2003) postula que o sujeito, ao aprender, está sempre se emocionando, vivenciando emoções. Esta emoção, quando apropriada e utilizada de forma estratégica, funciona como uma alavanca para o desenvolvimento do sujeito. A participação ativa, intencional, consciente e interativa, como sujeito que aprende, pode transformar tanto contexto social como o próprio sujeito. Ressaltamos que, nos processos formativos, essa dimensão não pode ser negligenciada. Já em termos mais macrossociológicos, percebemos que, apesar do estado atual do capitalismo contemporâneo, de cunho neoliberal, restringir o acesso ao trabalho aos mais pobres, contraditoriamente ele abre esses espaços de experimentação democrática que podem questioná -lo, negando alguns de seus princípios e práticas e alcançando micro transformações sociais relevantes.

Os contextos autogestionários são oportunidades, potencialidades que podem gerar empoderamento e transformação social, aprendizagem para os trabalhadores e trabalhadoras e, assim, contribuir para uma sociedade mais justa. 


\section{REFERÊNCIAS}

BAJOIT, G. Tudo muda: proposta teórica e análise de mudança sociocultural nas sociedades ocidentais contemporâneas. Ijuí: Ed. Ijuí, 1996.

BARROS, R.B. Dispositivo em ação: o grupo. Cad. Subjetividades, Vol.1, n'.1, p. 97-106, 1996.

BAUER, M.; AARTS, B. A construção do corpus: um princípio para a coleta de dados qualitativos. In: BAUER, M.; GASKELL, G. Pesquisa qualitativa com texto, imagem e som. Petrópolis: Vozes, p. 39-63, 2002.

BOURDIEU, P. Coisas ditas. São Paulo: Brasiliense, 1990.

ECONOMIA SOLIDÁRIA. Mapeamento Rio Grande do Sul. Brasília, Secretaria Nacional de Economia Solidária - SENAES/TEM, (Convênio Finep/Unitrabalho e Unitrabalho/Unisinos), 2008.

GAIGER, L. I. (Org). Sentidos e experiências da economia solidária no Brasil. Porto Alegre: Editora da UFRGS, 2004.

GARDNER, H. Mentes que lideram: uma anatomia da liderança. Porto Alegre: Artes Médicas Sul, 1996.

GRAMSCI, A. Escritos politicos. Rio de Janeiro: Civilização Brasileira, 2004.

GONZALES-REY, Fernando. Sujeito e Subjetividade. São Paulo: Thomson, 2003.

GUIMARÃES, G. Sindicalismo \& cooperativismo: a economia solidária em debate - transformações no mundo do trabalho. São Paulo: Unitrabalho, 2000.

ICAZA, A.M.S. Solidariedade, autogestão e cidadania: mapeando a economia solidária no Rio Grande do Sul. In: GAIGER, L. I. (Org.). Sentidos e experiências da economia solidária no Brasil. Porto Alegre: Editora da UFRGS, p.17-54, 2004.

KERNBERG, O. Ideologia, conflito e liderança em grupos e organizações. Porto Alegre: Artes Médicas Sul, 2000.

LEFÈVRE, F.; LEFÈVRE, A. M. C. Princípios básicos e conceitos fundamentais do discurso do sujeito coletivo. In: LEFÈVRE, F.; LEFÈVRE, A. M. C.; TEIXEIRA, J. J. V. O discurso do sujeito coletivo: uma nova abordagem metodológica em pesquisa qualitativa. Caxias do Sul: Universidade de Caxias do Sul, p.13-35, 2005. 
LEWIN, K. Problemas de dinâmica de grupos. São Paulo: Cultrix, 1978.

LISBOA, A.M. A socioeconomia solidária diante da grande transformação. Ciências Sociais Unisinos, Vol. 37, nº. 159, p. 27-57, 2001.

MAILHIOT, G. B. Dinâmica e gênese dos grupos. 7.ed. São Paulo: Duas Cidades, 1991.

MORIN, E. Ciência com consciência. Rio de Janeiro: Bertrand, 2000.

MOSCOVICI, S.; DOISE, W. Dissensões e consenso: uma teoria geral das decisões coletivas. Lisboa: Livros Horizonte, 1991.

SANTOS, B. S. Conhecimento prudente para uma vida decente: um discurso sobre as ciências revisitado. São Paulo: Cortez, 2004.

SENGE, P.M. A quinta disciplina: arte e prática da organização de aprendizagem. 17. ed. São Paulo: Best Seller, 2004.

SINGER, P. Introdução à economia solidária. São Paulo: Editora Fundação Perseu Abramo, 2002.

. Economia solidária. In: CATTANI, Antonio David (Org). A outra economia. Porto Alegre: Veraz, 2003.

SCHOLZ, Robinson Henrique; VERONESE, Marilia Verissimo. Liderança na economia solidária: o caso da cooperativa metalúrgica Cooperei. Economia Solidária e Ação Cooperativa, UNISINOS, Vol. 1, nº. 2, p.01-10, 2008.

SUAREZ, C. J. P. Como organizar empresas solidárias eficientes. Santafé de Bogotá: Ediciones Antropos, 1992.

VERONESE, M.V. A psicologia na transição paradigmática: um estudo sobre o trabalho na economia solidária. Porto Alegre, PUCRS, 226f. Tese (Doutorado em Psicologia), Pontifícia Universidade Católica do Rio Grande do Sul - PUCRS, Porto Alegre, 2004.

VILLEGAS, R. Doutrina e teoria em cooperativismo: o desafio face a realidade das cooperativas na América Latina. Série cooperativismo 3, São Leopoldo, Ano XIII, Vol. 8, n. 20, p. 79-95, 1979.

Recebido: 06/11/2013

Aprovado: 19/12/2013 